\title{
O Direito Humano ao Ambiente Sadio: perspectivas sobre a indivisibilidade entre os direitos ambientais e direitos humanos
}

\author{
The Human Right to the Healthy Environment: perspectives on the \\ indivisibility between environmental rights and human rights
}

Resumo: a discussão sobre como melhor proteger o ser humano e sua dignidade das injustiças perpetradas pelo desenvolvimento assimétrico das diferentes nações e sociedades se tornou um dos destaques da agenda internacional a partir do fim da Guerra Fria. Nesse contexto, começam a emergir, no âmbito das Nações Unidas, pautas de Direitos Humanos que anteriormente se encontravam limitadas ao campo do Direito Ambiental, como o direito humano ao ambiente sadio, ainda não reconhecido formalmente. Este artigo busca compreender quais são as conexões existentes entre os dois campos e se os direitos referentes ao Meio Ambiente devem ou não ser considerados indivisíveis em relação aos demais Direitos Humanos, sendo está uma das condições sugeridas pelo Conselho de Direitos Humanos da Organização das Nações Unidas (ONU). A discussão proposta por este artigo é de caráter teórico-conceitual, no intuito de fornecer maior clareza sobre as interseções existentes entre os dois campos mencionados previamente, $\mathrm{e}$ é realizada através de análise documental e bibliográfica.

Palavras-chave: Direitos Humanos; Direito Ambiental; Ambiente Sadio.

Abstract: the discussion on how to better protect human beings and their dignity from the injustices perpetrated by the economic inequality of different nations and societies has become a highlight of the international agenda since the end of the Cold War. In this context, Human Rights guidelines that previously were limited to the field of Environmental Law, as the human right to healthy environment, yet to be formally recognized, began to emerge within the framework of the United Nations. This article seeks to understand the connections between the two camps and whether the rights relating to the environment can or should be considered indivisible in relation to other human rights, as this is one of the conditions suggested by the United Nations Human Rights Council (UNHRC). The discussion proposed by this article is theoretical-conceptual and intends to provide greater clarity about the existing intersections between the two previously mentioned fields, and is developed through documental and bibliographic analysis.

Keywords: Human Rights; Environmental Law; Healthy Environment.

\section{Introdução}

Durante grande parte do século XX, a Guerra Fria tornou-se o foco central do debate nas organizações e conferências internacionais, freando pautas que, à época, eram consideradas de menor importância para 
os países centrais, que dominavam a formação da agenda internacional. No entanto, a queda do Muro de Berlim e o colapso da União Soviética, eventos de caráter simbólico, mas com impacto significativo na política internacional, iniciam um processo de mudança na agenda internacional: a emergência de novos temas, perspectivas e epistemologias. Entre estas inovações, Sato (2000) destaca as pautas de direitos humanos e do meio ambiente como algumas que receberiam grande atenção no pós-Guerra, principalmente à medida que a comunidade internacional buscava compreender o papel das desigualdades de natureza socioeconômica na perpetuação das injustiças que ameaçam a dignidade humana ${ }^{2}$. Neste contexto, os Direitos Humanos emergem como uma alternativa na busca da proteção dos seres humanos em situação de vulnerabilidade, principalmente aqueles sob a tutela de Estados em situação de fragilidade ou extrema pobreza (TRINDADE, 2003; BIELEFELDT, 2006; DONNELLY, 2009).

$\mathrm{Na}$ atualidade, os direitos que compõem o Direito Internacional dos Direitos Humanos (DIDH) são comumente divididos em três categorias (ou gerações) referentes aos tipos de proteção ou garantias que buscam. A primeira geração dos Direitos Humanos engloba os direitos civis e políticos, no que tange às liberdades individuais. Entre eles destaca-se o direito ao voto, as liberdades de expressão e imprensa, a presunção de inocência (habeas corpus) e um dos direitos centrais para este trabalho: o direito à vida, inicialmente proposto em sentido restrito, como a não-execução de forma arbitrária e, mais atualmente, revisto em seu sentido mais amplo (TRINDADE, 2003; ABOUHARB; CINGRANELLI, 2007). Esta primeira geração, em sua composição, aborda direitos de caráter negativo, ou seja, no que diz respeito ao cumprimento destes direitos, é necessária a ausência de ação estatal, sendo o Estado, neste sentido, a maior ameaça para tais direitos (DONNELLY, 2003; LOUREIRO; SALLES, 2017).

A segunda geração dos direitos humanos, por sua vez, engloba os direitos econômicos e sociais, de caráter positivo, que exigem diretamente a ação do Estado para garantir proteção e condições adequadas para os indivíduos. Entre estes direitos, destacam-se o direito à educação, ao trabalho, ao lazer e, indispensável para este trabalho, o direito à saúde. Assim como o direito à vida, o direito à saúde passou por diversas atualizações e reformulação desde seu reconhecimento. Ganhando força a partir de eventos marcantes, como a promoção dos direitos à saúde da mulher e o combate à pandemia do HIV/AIDS (GRUSKIN; TARANTOLA, 2005; MARKS, 2013), o direito humano à saúde ganha um sentido ampliado, seguindo o definido pela Constituição da Organização Mundial da Saúde (OMS), que entende a saúde como "um estado de bem-estar físico, mental e social e não somente a ausência de doença ou enfermidade, além de afirmar que desfrutar do mais alto padrão de saúde possível é um dos direitos de todo ser humano sem distinção de raça, religião, credo ou condição social ou econômica" (LOUREIRO; SALLES, 2017, p. 5).

Por fim, a terceira geração representa os direitos de solidariedade, que são fruto da solidariedade entre as distintas sociedades e nações, concretizando, de certa forma, um conjunto de direitos que

\footnotetext{
2 Segundo Donnelly (2009), apesar de uma definição de dignidade humana se encontrar ausente nos principais dispositivos de direitos humanos, é possível concluir que "o argumento pela dignidade humana é simplesmente que ser humano torna alguém valoroso ou digno de respeito" (p. 11). Portanto, para o autor pode-se inferir que os Direitos Humanos "especificam certas formas de respeito social - bens, serviços, oportunidades e proteções devidas a cada pessoa como um aspecto de direito - atribuídas por esta dignidade" (p.12). Enders (2010), contribuindo com esta definição, argumenta que o conceito de dignidade humana está diretamente vinculado ao princípio de raison d'être (razão de ser ou existir), se tratando de garantias básicas para os indivíduos sustentadas na ideia de que estes possuiriam um "direito a ter direitos" simplesmente por serem humanos.
} 
reconhecem as obrigações das nações e grupos que possuem mais condições e recursos em relação aos menos favorecidos. Donnelly (2003) acredita que esta geração seria uma classe ampla de direitos coletivos a serem assegurados pelo Estado contra a própria ação estatal, mas, além disso, são direitos que exigem a participação da própria sociedade civil, seja por meio dos diferentes grupos sociais, dos indivíduos em sua particularidade ou até mesmo das indústrias e empresas privadas. Destacam-se os direitos à participação no patrimônio comum da humanidade, ao desenvolvimento, à paz e o direito ao ambiente sadio (LOUREIRO; SALLES, 2017), tema central deste artigo e foco de uma discussão recente sobre a necessidade de reconhecê-lo no âmbito da Organização das Nações Unidas (ONU).

Assim, o direito ao ambiente sadio, ainda não reconhecido formalmente como um direito humano pelo Conselho de Direitos Humanos da ONU, tem emergido como pauta importante para a comunidade internacional, recebendo apoio de organizações importantes para o debate dos Direitos Humanos, como o Human Rights Watch (ORELLANA, 2018). Este artigo se propõe, então, a estudar a existência de documentos e instrumentos legais que façam referência a um possível direito humano ao meio ambiente sadio, retomando convenções e tratados internacionais em vigência, utilizando o método da análise documental. Além disso, será elaborada uma análise bibliográfica de artigos e livros de demais autores que versem sobre o tema, em busca de diferentes perspectivas sobre este direito humano.

\section{Os direitos à vida e saúde: uma sólida fundação de direitos humanos}

Donnelly (2003) afirma que o Direito Internacional dos Direitos Humanos (DIDH) consagra as obrigações de protegê-los como irredutíveis. Logo, se os direitos geram obrigações irredutíveis, eles são direitos irredutíveis. $E$, levando em consideração que proteger um direito não exime um Estado de proteger os demais, o gozo de uma vida digna e de qualidade exige, de fato, que estes direitos sejam tratados como insubstituíveis e igualmente necessários (TRINDADE, 2003; LOUREIRO; SALLES, 2017), perspectivas consagradas pelas resoluções nº 39/145 de 1984 e 41/117 de 1986 da Assembleia Geral da ONU. Neste sentido, reconhece-se, também, que, a fim de integrar o corpo do DIDH, é necessário que um novo direito humano seja reconhecido como parte indivisível do mesmo.

Para compreender como o meio ambiente se encaixaria neste corpo complexo de direitos humanos, é necessário atentar ao histórico recente do desenvolvimento de alguns direitos mais tradicionais, como o direito à vida e o direito à saúde, amplamente difundidos e universalmente aceitos. O desenvolvimento e ampliação destes direitos acaba por formar, intencionalmente ou não, uma estrutura sólida para fundamentar uma postura mais progressista e abrangente das medidas necessárias para proteger a dignidade humana (TRINDADE, 2003; BIELEFELDT, 2006).

O direito humano à vida é um direito de primeira geração universalmente reconhecido, cujo gozo é condição necessária para o exercício dos demais. Todavia, este direito inicialmente é formulado como uma proteção mínima, referente à preservação da vida dos indivíduos, sejam eles cidadãos ou não, contra execuções arbitrárias do Estado (TRINDADE, 2003). Um direito humano de caráter negativo, como os demais de sua geração, possuía um caráter restritivo de não-intervenção do Estado na vida dos indivíduos, mas que se tornou alvo de contestações mais recentes sobre seu caráter excessivamente mínimo. 
O Comitê de Direitos Humanos ${ }^{3}$, que atua em obediência ao Pacto dos Direitos Civis e Políticos da ONU, enfatiza que o direito humano à vida em sentido amplo - o "direito supremo do ser humano" - requer medidas positivas por parte dos Estados. De modo semelhante, a Comissão Interamericana de Direitos Humanos chama a atenção para o caráter obrigatório desse direito e adverte contra a privação arbitrária da vida (TRINDADE, 2003, p. 177).

Com a expansão das responsabilidades geradas pelo direito humano à vida, emergem novas interpretações, como a da Comissão Europeia de Direitos Humanos, que argumenta que os Estados possuem "a obrigação positiva e mais abrangente de adotar as medidas cabíveis no sentido de proteger a vida" (TRINDADE, 2003, p. 178). Ao redefinir este como um direito também de caráter positivo, é possível enxergar as relações claras que são construídas com o Pacto Internacional dos Direitos Econômicos, Sociais e Culturais, que reconhecem, nos artigos 11 e 12, que o Estado possui a obrigação de garantir um padrão de vida e saúde adequado para a população (BRASIL, 1992).

Diretamente vinculado a este primeiro direito, o direito humano à saúde, que possui uma formulação significativamente recente, é um direito de segunda geração que conquistou rapidamente uma posição de destaque e prestígio na comunidade internacional, sendo amplamente reconhecido. Desde a fundação da ONU, em 1945, reconhece-se a responsabilidade internacional de promover a saúde, protegendo os indivíduos de eventuais ameaças, como pandemias e endemias. Entretanto, neste momento, a saúde ainda não era vista como parte integrante dos Direitos Humanos (GRUSKIN; TARANTOLA, 2005; MARKS, 2013; LOUREIRO; SALLES, 2017).

A Organização Mundial da Saúde (OMS), em sua Constituição de 1946, reconheceu a saúde como "um estado de bem-estar físico, mental e social e não somente a ausência de doença ou enfermidade" (LOUREIRO; SALLES, 2017, p. 5) e que, independente de raça, religião, credo ou condição social ou econômica, é um direito de todo ser humano desfrutar do mais alto padrão de saúde possível. Tal perspectiva, assim como a leitura mais abrangente sobre o direito humano à vida, está alinhada ao descrito pelo Artigo 12 do Pacto Internacional dos Direitos Sociais, Econômicos e Culturais (BRASIL, 1992).

Apesar disso, foi somente em 1978, com a Declaração de Alma-Ata sobre Cuidados Primários de Saúde, que o direito à saúde foi consagrado pela comunidade internacional como um direito humano fundamental. A Declaração, fruto da Conferência Internacional sobre Cuidados Primários de Saúde, realizada neste mesmo ano na antiga União Soviética, reforça a interpretação de saúde definida pela Constituição da OMS e reconhece que as disparidades entre países desenvolvidos e em desenvolvimento no campo da saúde são uma preocupação global, exigindo cooperação e prioridade para os mais vulneráveis a fim de garantir a proteção dos seres humanos (OMS, 1978; MARKS, 2013).

Assim como o direito à vida, para garantir o direito à saúde, é preciso também reconhecer a obrigação do Estado de não praticar qualquer ato que ponha em risco a saúde dos indivíduos e de adotar

\footnotetext{
3 O Comitê de Direitos Humanos não deve ser confundido com a antiga Comissão de Direitos Humanos e com seu sucessor, o Conselho de Direitos Humanos, corpo que faz parte da Organização das Nações Unidas. O Comitê de Direitos Humanos é "o corpo de especialistas independentes que monitora a implementação do Pacto Internacional sobre Direitos Civis e Políticos por seus Estados membros". O Comitê se reúne em Genebra cerca de três vezes por ano para propor comentários e revisões sobre as normas vigentes de direitos humanos. Disponível em: <https://www.ohchr.org/EN/HRBodies/CCPR/Pages/CCPRIntro.aspx>. Acesso em 7 de janeiro de 2019.
} 
todas as medidas possíveis para sua proteção e preservação (TRINDADE, 2003; MARKS, 2013). Não se limitando ao tratamento de doenças e enfermidades, o direito à saúde inclui a atenção primária à saúde e a promoção de um padrão de vida sadio e de qualidade, reconhecendo a necessidade de intervenções estatais na área, principalmente por meio da construção de políticas públicas apropriadas ${ }^{4}$.

Assim como o direito à vida, para garantir o direito à saúde, é preciso também reconhecer a obrigação do Estado de não praticar qualquer ato que ponha em risco a saúde dos indivíduos e de adotar todas as medidas possíveis para sua proteção e preservação. (TRINDADE, 2003; MARKS, 2013). Não se limitando ao tratamento de doenças e enfermidades, o direito à saúde inclui a atenção primária à saúde e a promoção de um padrão de vida sadio e de qualidade, reconhecendo a necessidade de intervenções estatais na área, principalmente por meio da construção de políticas públicas apropriadas.

\section{Meio ambiente e direitos humanos}

Trindade (2003) argumenta que a lei ambiental deve ser incluída ao DIDH como um direito humano de terceira geração, sob a prerrogativa de que a proteção do ser humano envolve, num escopo mais amplo, a proteção de toda a biosfera e de um padrão de vida adequado, já que a sobrevivência dos seres humanos depende diretamente das condições do ambiente em que habita. Recentemente, a comunidade internacional começa a enxergar que a degradação ao meio ambiente se apresenta como uma ameaça direta à saúde humana. Apesar disso, o debate sobre a preservação do meio ambiente encontra fortes resistências por parte de diversos setores da sociedade.

No ano de 2016, segundo Orellana (2018), pelo menos 200 ativistas que lutavam pelo meio ambiente e pelos direitos à terra foram assassinados em 24 países, grande parte deles na América do Sul. Luño (1991) defende que, no curso dos últimos anos, poucas questões geraram tanta inquietude como as relações do homem com o meio ambiente em que habita e que condiciona sua existência. A tensão entre natureza e sociedade torna-se visível quando observamos que, ao longo da história humana, a compreensão de desenvolvimento tecnológico frequentemente coincide com o domínio e a exploração desregulada dos recursos naturais.

O argumento por um desenvolvimento econômico sustentado na ampla exploração dos recursos naturais que, em muitos casos, acaba levando à contaminação e degradação do meio ambiente, ainda está presente em nossa sociedade, apesar das repercussões drásticas que tais práticas irresponsáveis têm apresentado. Desastres ambientais ao longo do planeta demonstram a importância de proteger a salubridade do meio ambiente antes que a qualidade de vida dos indivíduos se encontre em risco extremo e irreversível (GIONGO, 2010; LOUREIRO; SALLES, 2017).

Ainda, Cançado Trindade (1993), ao advogar pela expansão do direito ao refúgio para vítimas de catástrofes ambientais, destaca a importância de zelar pela proteção ambiental como vital para os seres humanos, compreendendo que estes desastres causam danos a longo prazo e possuem a capacidade de alterar a vida dos sujeitos indefinidamente. É possível compreender, portanto, que o

\footnotetext{
4 Bucci (2001) elabora um debate interessante sobre a necessidade da elaboração de políticas públicas voltadas à concretização dos direitos humanos, pois elas seriam capazes de transformar estes princípios orientadores em regras capazes de constituir obrigações jurídicas.
} 
Direito Ambiental versa sobre questões que ultrapassam o enquadramento de somente um indivíduo e somente um período definido de tempo, podendo ser compreendido como trans-individual e transgeracional (TRINDADE, 1993; GIONGO, 2011).

No Brasil, a proteção ao meio ambiente se encontra presente em diversos instrumentos jurídicos, a partir da própria Constituição Federal de 1988 (CF88), que prevê o direito ao meio ambiente ecologicamente equilibrado como direito fundamental dos brasileiros e brasileiras em seu artigo 255 (BRASIL, 1988). A salubridade ambiental foi consagrada como parte da política de saúde pública a partir da aprovação da Lei 8.080/1990, que instituiu o Sistema Único de Saúde (SUS), cujo artigo $3^{\circ}$ afirma que os determinantes e condicionantes da saúde incluem, "entre outros, a alimentação, a moradia, o saneamento básico, o meio ambiente, o trabalho, a renda, a educação, a atividade física, o transporte, o lazer e o acesso aos bens e serviços essenciais" (BRASIL, 1990). Esta leitura, de caráter abrangente, foi reforçada pelo Plano Nacional de Saneamento Básico (Plansab), instituído 23 anos depois pela presidente Dilma Rousseff (MINISTÉRIO DAS CIDADES, 2013). A legislação nacional reconhece que é necessário preservar o meio ambiente para que a dignidade e a saúde humanas não sejam prejudicadas 5 .

O documento "Direitos Humanos e o Meio Ambiente: Consulta Regional sobre a Relação Entre Obrigações de Direitos Humanos e Proteção Ambiental, com Foco nos Direitos Ambientais Constitucionais", fruto de uma consulta realizada pelo Especialista Independente em direitos humanos e meio ambiente das Nações Unidas, em conjunto com o Programa das Nações Unidas para o Meio Ambiente (PNUMA), o Escritório do Alto Comissariado das Nações Unidas para os Direitos Humanos (ACNUDH) e o Legal Resources Centre (LRC) da África do Sul, demonstra que o Brasil não é um caso isolado. Segundo a publicação, mais de 90 nações possuem alguma forma de direito ao meio ambiente sadio e à proteção ambiental previsto em suas constituições, incluindo mais de 30 países do continente africano. Cerca de dois terços destes direitos fazem referência ao direito à saúde e um quarto utiliza termos semelhantes ao meio ambiente ecologicamente equilibrado "formulações alternativas incluem direitos ao meio ambiente limpo, seguro, favorável ou saudável".

Ao reconhecer que a salubridade ambiental é diretamente ligada à saúde dos indivíduos, reconhece-se, por consequência, que a vida humana depende da mesma, tornando possível argumentar que, por estar vinculado diretamente a estes dois direitos humanos fundamentais, vida e saúde, a proteção ao meio ambiente poderia integrar o Direito Internacional dos Direitos Humanos.

O direito humano a um ambiente sadio engloba as dimensões ambientais dos direitos civis, culturais, econômicos, políticos e sociais, e protege os elementos centrais do ambiente natural que possibilita uma vida de dignidade. Diversos ecossistemas e água, ar e solos limpos são indispensáveis para a saúde humana e a segurança. O direito também protege os espaços cívicos para que indivíduos possam engajar em diálogos sobre política ambiental. Sem ele, políticas governamentais muitas

5 Todavia, Ziglio e Comegna (2013) indicam que nem sempre essa legislação ambiental nacional parece ser implementada e fiscalizada à risca.

6 Disponível em: <http://srenvironment.org/wp-content/uploads/2014/11/Johannesburg-consultation-report-final1.pdf>. Acesso em 12 de janeiro de 2019. 
vezes atendem os interesses dos poderosos, não do público, e certamente não dos politicamente marginalizados (ORELLANA, 2018, n.p., tradução nossa).

A Conferência de Estocolmo sobre o Meio Ambiente", organizada em 1972 pela ONU, "foi o grande ponto de partida para a conscientização ecológica e a necessidade da cooperação internacional para a proteção transfronteiriça do meio ambiente" (CALSING, 2011, p. 172) e contou com a participação de 114 países. A Conferência foi o primeiro esforço global de elaborar um projeto transnacional para a preservação do meio ambiente, destacando a importância de implementação doméstica dos princípios traduzidos pelo seu documento principal, a Declaração de Estocolmo.

A Declaração, já em seu Princípio 1, afirma que o ser humano possui o direito à liberdade e ao meio ambiente sadio. Os seis princípios seguintes versam sobre a necessidade de proteger a terra, o ar, a água, o solo, a fauna e a flora, enquanto os princípios entre 8 e 25 elaboram instrumentos para a proteção ambiental baseados na ciência, tecnologia, ação conjunta, informação, gestão ambiental e responsabilização dos Estados por danos ambientais, pois estes possuiriam a capacidade de cobrar indenizações e aplicar sanções. Calsing (2011), atenta para o Princípio 21, que reconhece o direito soberano dos Estados para explorar seus recursos naturais, desde que o uso destes recursos não prejudique os demais ou seus habitantes:

Estados possuem, em conformidade com a Carta das Nações Unidas e com os princípios do Direito Internacional, o direito soberano de explorar seus próprios recursos de acordo com sua própria política ambiental, e a obrigação de assegurar que as atividades dentro de sua jurisdição ou seu controle não causem danos ao meio ambiente de outros Estados ou de áreas situadas fora de jurisdição nacional (ONU, 1972).

Ziglio e Comegna (2013) enxergam a produção do Relatório Brundland, elaborado pela Comissão Mundial sobre Meio Ambiente e o Desenvolvimento da ONU em 1987, o ponto inicial da discussão sobre o desenvolvimento sustentável no âmbito internacional. Crítico às nações industrializadas que ostentavam altos índices de poluição, o Relatório ressaltou a necessidade conjunta de zelar pela harmonização entre eficiência econômica, justiça social e meio ambiente.

Esse relatório deixou bem clara sua proposta: a exploração dos recursos naturais, os investimentos econômicos e o desenvolvimento tecnológico não devem comprometer a construção de um futuro justo, seguro e próspero, embasado na responsabilidade comum com o ambiente do planeta (ZIGLIO; COMEGNA, 2013, p. 515).

O Relatório traz consigo uma das primeiras definições de desenvolvimento sustentável, compreendendo este como aquele que fosse capaz de atender às necessidades do presente sem negligenciar os anseios sobre as futuras gerações atenderem suas próprias necessidades (FIORE; ZIGLIO, 2013; ZIGLIO; COMEGNA, 2013).

Em um momento importante para a agenda do Direito Internacional Ambiental, a ONU organizou, no Rio de Janeiro, a Conferência das Nações Unidas sobre Meio Ambiente e Desenvolvimento,

7 O PNUMA foi um dos resultados da Conferência de Estocolmo (FIORE; ZIGLIO, 2013). 
popularmente conhecida como Eco-92 ou Rio-92, que contou com a participação de 178 Estados e mais de 1400 organizações não-governamentais (ONGs) produziu a Declaração do Rio, que:

contém 27 princípios gerais que confirmam os de Estocolmo e introduzem novas regras consuetudinárias. Resumidamente, o artigo 10 ressalta a importância da participação da sociedade na proteção do meio ambiente; o artigo 11 pede a adoção de medidas mais eficazes para esta proteção; o artigo 13 versa sobre a responsabilidade dos Estados por danos ambientais causados em seu território; e os artigos 15 a 18 reconhecem os princípios da precaução, poluidor-pagador e da assistência internacional (CALSING, 2011, p. 174).

A Agenda 21, o plano de ação para a implementação dos valores da Declaração do Rio, também assinado na Rio-92, consagrou conceitos importantes para os países em desenvolvimento, que ainda possuíam setores industriais relativamente tardios em relação aos países industrializados, como o desenvolvimento sustentável e o princípio das responsabilidades comuns, porém diferenciadas entre os países para a proteção do meio ambiente (VARGAS, 2000; LOUREIRO; SALLES, 2017). Este segundo princípio é fundamental por possibilitar uma interpretação de que os países industrializados, "que exportam pobreza e poluição para o planeta" (ZIGLIO; COMEGNA, 2013), possuem responsabilidades maiores que os demais países na produção de tecnologias sustentáveis e de políticas ecologicamente responsáveis, pois estes já haveriam usufruído dos recursos naturais de maneira predatória por um longo período para consolidar suas indústrias e economias nacionais.

Fiore e Ziglio (2013, p. 9) destacam que a Rio-92 propõe à sociedade civil e à comunidade internacional "o desafio de regular a ação humana no planeta" e, ao mesmo tempo, aprofundar e aplicar o conceito de desenvolvimento sustentável, missão que tem sido levada à frente por fóruns internacionais como a Cúpula Mundial sobre Desenvolvimento Sustentável de Johanesburgo (Rio +10) e a Conferência das Nações Unidas sobre Desenvolvimento Sustentável (Rio +20).

Os eventos mundiais, aqui relembrados, abriram um acmpo heterogêneo de perspectivas, marcados pela gama de interesses em torno de um único objetivo: a continuidade do processo de apropriação do meio ambiente. [...] O ponto de inflexão: a necessidade de um novo paradigma de desenvolvimento permanece (FIORE; ZIGLIO, 2013, p. 9).

No entanto, o reconhecimento internacional destes princípios que destacam a importância dos recursos naturais e do meio ambiente para a sobrevivência humana reforça a validade do direito ao ambiente sadio como um direito humano de caráter fundamental, indivisível e insubstituível. Autores como Trindade (2003), Calsing (2011) e Giongo (2010) descrevem o direito ao ambiente sadio como um direito humano de terceira geração, de caráter transnacional, trans-individual, comunitário e difuso, necessitando, antes de tudo, da cooperação dos indivíduos e da sociedade.

Este direito, no entanto, como diversos outro direito semelhante, exigiria ação estatal para fiscalizar atividades que pudessem colocar em risco a saúde ambiental e a inação estatal de não a colocar em risco pelas mãos do próprio Estado. As recorrentes crises ambientais, em sua grande maioria causadas por reflexos da ação humana, colocam em risco a estabilidade das sociedades 
e a vida dos indivíduos e requerem o reconhecimento deste direito humano pela comunidade internacional, sua absorção pelos estados-nacionais e a elaboração de políticas públicas capazes de efetivá-lo, além da reconstrução da consciência dos seres humanos sobre sua relação com o meio ambiente, para que compreendam a necessidade fundamental de uma relação menos predatória com a natureza (BUCCI, 2001; LOUREIRO; SALLES, 2017).

\section{Observações sobre as necessidades para o meio ambiente sadio}

Atualmente, apesar da emergência do debate sobre as questões ambientais, a preocupação de certos governos em elaborar legislações capazes de prevenir e reduzir danos ao meio ambiente, e certas vitórias de ativistas, ainda permanece a percepção de baixo poder de fiscalização internacional (CALSING, 2011; GOMES, 2017). Desastres ambientais continuam sendo uma realidade constante em diversas regiões do planeta, mesmo em países que reconhecem direitos constitucionais ao ambiente sadio, e, nos casos mais extremos, indivíduos em situação de extrema vulnerabilidade permanecem sendo obrigados a abandonar seus lares e migrar para preservar suas vidas (CALSING, 2011; LEAL, 2017; LOUREIRO; SALLES, 2017).

Bucci (2001) argumenta que os direitos humanos se apresentam como princípios orientadores para a formulação de políticas e normas, mas não possuem, por si só, capacidade de gerar obrigações jurídicas para os indivíduos e para as instituições do Estado. Seria necessário, portanto, elaborar instrumentos capazes de transformar os direitos humanos em regras de fato, capazes de gerar mudanças reais na sociedade e no comportamento estatal. A construção de políticas públicas apropriadas parece ser, segundo a autora, o caminho mais apropriado para tornar estes princípios em ferramentas práticas. Se distanciando de perspectivas mais liberais e reafirmando a perspectiva de indivisibilidade dos direitos humanos, afirma que seria impossível garantir direitos civis e políticos sem que os demais fossem protegidos e tais garantias fossem a realidade dos indivíduos.

Como poderia, por exemplo, um analfabeto exercer plenamente o direito à livre manifestação do pensamento? Para que isso fosse possível é que se formulou e se positivou nos textos constitucionais e nas declarações internacionais o direito à educação. Na mesma linha, como se pode dizer que um sem-teto, que mora debaixo da ponte, exerce o direito à intimidade (artigo $5^{\circ}, \mathrm{X}$, da Constituição brasileira)? Isso será uma ficção enquanto não lhe for assegurado o direito à moradia, hoje constante do rol de direitos sociais do artigo $6^{\circ}$ da Constituição (BUCCl, 2001, p. 8).

O direito humano ao ambiente sadio, como qualquer outro direito humano, pode ser incluso nesta narrativa. Como garantir o direito à vida sem condições adequadas de salubridade ambiental ${ }^{8}$ ou, em escalas mais graves, como preservar a vida humana sem condições suficientes para garantir também a alimentação, saúde e segurança? É necessário, portanto, que além de reconhecer direitos constitucionais ao meio ambiente ecologicamente equilibrado, os países construam estruturas capazes de efetivar estes direitos, ou seja, políticas públicas de caráter ambiental.

\footnotetext{
8 Valvassori e Alexandre (2012) compreendem que "a salubridade ambiental pode ser entendida como a qualidade ambiental capaz de prevenir doenças que são veiculadas pelo meio ambiente e de aperfeiçoar as condições favoráveis à saúde da população urbana e rural” (p. 2).
} 
Tais políticas se mostram necessárias desde a fiscalização das atividades econômicas e industriais, para reduzir a exploração excessiva dos recursos naturais e buscar alternativas mais sustentáveis para tais práticas, até, nos casos de acidentes ou crimes ambientais, a redução de danos ao meio ambiente e investigação, sanção e responsabilização das partes envolvidas. Estes são mecanismos complexos, mas necessários para a preservação da salubridade ambiental, a fim de evitar novos desastres e reduzir o impacto ambiental causado pelas atividades humanas, considerando a importância do meio ambiente para a sobrevivência e garantia de uma vida digna.Ziglio e Comegna (2013, p. 521) apontam que a existência de leis ambientais, por si só, parece não ser suficiente para tal, tornando necessário "o cumprimento da legislação vigente por parte do Estado e dos agentes econômicos; promover alternativas sustentáveis para a utilização dos recursos naturais e, finalmente, apoiar o fortalecimento de movimentos sociais e organizações", principalmente as que possuam como meta a preservação do meio ambiente e justiça ambiental. A importância de incluir a sociedade civil nas negociações sobre o direito humano ao ambiente sadio é um aspecto fundamental da natureza deste direito como de terceira geração, que não se limita às competências e ações do Estado.

Ao incluir movimentos sociais e organizações civis na construção de mecanismos de controle social para a proteção do meio ambiente e utilização sustentável dos recursos naturais, reduz-se a possibilidade de que agentes econômicos, em sua grande maioria, permeados pela lógica de um capitalismo exploratório e ecologicamente insustentável, possam realizar suas atividades econômicas de forma predatória.

Além disso, para além dos limites fronteiriços dos Estados nacionais, argumentos favoráveis à fiscalização internacional de práticas ambientais apontam a necessidade de que organismos internacionais consigam atuar e intervir para evitar danos severos ao meio ambiente e proteger as populações que se encontram em situação de vulnerabilidade ambiental (GOMES, 2017; LEAL, 2017). A preservação, assim como sugerido pela Agenda 21 da Rio-92, exige a responsabilidade de todos os países dentro de suas possibilidades, não se restringindo a fronteiras e identidade nacionais. Apesar disso, a Agenda 21 não possui força de lei e, portanto, se trata apenas de um princípio orientador capaz de inspirar a produção de novos dispositivos legais no futuro.

O meio ambiente é único e não respeita limites fronteiriços ou políticos (CASLING, 2011), demonstrando a necessidade por cooperação internacional de caráter multilateral ${ }^{9}$, e contando com a colaboração mundial entre organizações internacionais, governos e sociedades como parte indispensável para o sucesso de uma ação global para o meio ambiente, necessitando abordar aspectos como tecnologia, ciência e gestão. Acidentes e crimes ambientais não se limitam a fronteiras geográficas e políticas, causando danos a diferentes grupos sociais e nacionais de diversos países. Somente por meio de uma atuação estatal eficaz e de fiscalização e ação conjunta será possível garantir a salubridade do meio ambiente em escala global.

A maioria destes princípios já é reconhecida pela comunidade internacional e pelos Estados de forma individual, no entanto, no que tange às políticas públicas e a responsabilização de indivíduos, companhias e Estados, a situação ainda é precária. Com a exceção de mais raros e extremos casos, o

\footnotetext{
9 Ruggie (1992, p. 572, tradução nossa) compreende multilateralismo como a coordenação de "relações entre três ou mais Estados de acordo com princípios de conduta generalizados".
} 
processo de punição e sanção às más práticas ambientais ainda se mostra ausente em diversos países e, principalmente, no campo do Direito Internacional (LOUREIRO; SALLES, 2017; GOMES, 2017).

\section{Conclusões}

De acordo com a proposta deste artigo, foi realizado um levantamento sobre normas e tratados internacionais que versem sobre o direito ao ambiente sadio. Os resultados encontrados sugerem que há uma sólida base teórica e legal para sustentar o reconhecimento deste direito humano, de caráter fundamental, transnacional, trans-individual e difuso. Sua classificação mais adequada, por exigir ação por parte de todas as sociedades em todas as nações, reforça a opinião trazida por autores como Casling (2011) e Trindade (2003) de que este seria um "direito de solidariedade" ou de terceira geração, que exigem responsabilidade social e ação estatal a fim de garantir sua efetivação.

Apesar disso, há uma preocupante ausência de procedimentos e mecanismos em organizações internacionais que sejam capazes de fiscalizar, diagnosticar, responsabilizar e punir violadores deste direito humano, indicando que, além do reconhecimento, é necessário construir instrumentos adequados para garantir sua implementação. O comprometimento com este novo direito exige a construção de um mecanismo de efetivação que seja capaz de solucionar as adversidades e desafios propostos por um problema que não se limita a fronteiras e identidades nacionais.

Em relação à análise documental, observa-se a presença de elementos que remetem ou abordam diretamente a questão do saneamento ambiental desde a Declaração de Alma-Ata, que reconhece a necessidade de não somente oferecer cuidados para os enfermos como também zelar para garantir a saúde dos indivíduos, incluindo uma responsabilidade global e coletiva para a saúde. De maneira semeIhante, cerca de uma centena de Estados possuem, em suas constituições nacionais, referências a um direito ao saneamento ambiental, ao meio ambiente ecologicamente equilibrado ou outras formulações similares, o que sugere que este direito estaria, de certa forma, incorporado às legislações domésticas.

A presença de documentos nacionais e internacionais que vinculam o direito ao ambiente sadio diretamente às questões da vida e da saúde, ambos amplamente reconhecidos como direitos humanos dotados de prestígio na comunidade internacional, reforçam a coerência de tê-lo como parte integrante do Direito Internacional dos Direitos Humanos. Sem a preservação do meio ambiente a garantia da saúde dos indivíduos e, em escalas muito mais drásticas, a sobrevivência humana se tornam inviáveis. Este, em teoria, se posiciona para ser mais um direito humano amplamente adotado, apesar das barreiras encontradas até o momento.

Este artigo conclui, ainda, que a proteção do meio ambiente é, ou deveria ser, uma preocupação de escala global e, como desastres e crises ambientais não se limitam às fronteiras políticas e identidades nacionais, a responsabilização dos indivíduos, companhias e Estados é uma necessidade para garantir a efetivação deste direito humano, princípios reconhecidos pela Declaração de Estocolmo e pelos documentos produzidos durante a Conferência das Nações Unidas sobre Meio Ambiente e Desenvolvimento.

Recomenda-se, ainda, a cooperação internacional multilateral, utilizando do conhecimento e dos recursos produzidos pela ciência, tecnologia, informação e gestão, e a elaboração de políticas públicas e legislação doméstica que incluam, de maneira abrangente e enfática, estratégias que 
visem reduzir os danos provocados pela exploração insustentável dos recursos naturais, promovida por um sistema capitalista desregulado e insustentável. Nesse sentido, mostra-se necessário que o Estado não tome decisões ou realize atividades prejudiciais ao ambiente, que este aja para garantir a preservação ambiental e que a população cumpra sua devida parte, respeitando e zelando pelo meio ambiente. A existência de atividades econômicas e industriais que promovem um uso excessivo e abusivo dos recursos naturais não somente reforça a necessidade por fiscalização, como também devem servir como incentivo para a ação conjunta para o desenvolvimento de tecnologias, conhecimentos, práticas e mudanças de comportamento que sejam mais compatíveis com a preservação do meio ambiente, possibilitando a concretização do princípio do desenvolvimento sustentável.

Como afirmado anteriormente, o abuso dos recursos naturais e a degradação do meio ambiente causam danos para além das distinções entre nacionalidades, etnias, raças, grupos sociais e culturas. Todas as sociedades, portanto, possuem o dever de zelar pelo meio ambiente, mas, levando em consideração o princípio das responsabilidades comuns, porém diferenciadas, os países desenvolvidos, que mais exploraram o ambiente e retiraram dele recursos não-renováveis, possuem um papel ainda mais indispensável para garantir o sucesso do Direito Internacional Ambiental e das políticas, organizações e demais instituições que eventualmente possam surgir deste regime internacional. O princípio das responsabilidades comuns, porém diferenciadas, ainda, reforça a interpretação de que o direito humano ao ambiente sadio seria um direito de solidariedade, sustentado em um esforço colaborativo de todas as sociedades, de todas as nações e na ação dos Estados para fiscalizar, implementar e garantir a manutenção deste direito humano fundamental.

\section{Referências}

ABOUHARB, Rodwan M.; CINGRANELLI, David. Human Rights and Structure Adjustment. Cambridge, Reino Unido: Cambridge University Press, 2007.

BIELEFELDT, Heiner. Access to Water, Justice and Human Rights. In: RIEDEL, Eibe H.; ROTHER, Peter. The Human Right to Water. Berlim: BWV Verlag, 2006. p. 49-63.

BRASIL. Constituição da República Federativa do Brasil de 1988. Disponível em: http://www.planalto.gov.br/ccivil_03/constituicao/constituicaocompilado.htm. Acesso em: 12 jan. 2019.

BRASIL. Decreto n 591, de 6 de julho de 1992. Disponível em: http://www.planalto.gov.br/ccivil_03/ decreto/1990-1994/do591.htm. Acesso em: 12 jan. 2019.

BRASIL. Lei 8.080, de 19 de setembro de 1990. Disponível em: http://www.planalto.gov.br/ccivil_03/ Leis/L808o.htm. Acesso em: 12 jan. 2019.

BUCCI, Maria Paula Dallari. Buscando um Conceito de Políticas Públicas para a Concretização dos Direitos Humanos. In: BUCCI, Maria Paula Dallari et al. Direitos humanos e políticas públicas. São Paulo: Pólis, 2001. p. 5-16.

CALSING, Renata de Assis. O Direito Fundamental ao Meio Ambiente Sadio: convergência da proteção ambiental nos âmbitos nacional e internacional. Revista Nomos, Fortaleza, v. 30, n. 1, p. 161-177, 2010.

DONNELLY, Jack. Universal Human Rights in Theory \& Practice. 2. ed. Ithaca: Cornell University Press, 2003. 
DONNELLY, Jack. Human Dignity and Human Rights. Genebra: Geneva Academy of International Humanitarian Law and Human Rights, 2009.

FIORE, Sedenir; ZIGLIO, Luciana Aparecida. Historiografia ambiental: de predador à presa. História e-História, [S. l.], v. 1, p. 1-16, 2013.

GIONGO, Rafaela Luiza Pontalti. Direito ao Meio Ambiente e Qualidade de Vida: reflexões para uma sociedade humana e ecologicamente viável. Veredas do Direito, Belo Horizonte, v. 7, n. 13/14, p. 75-100, jan./dez. 2010.

GOMES, Carla Amado. Ambiente e Crimes contra a Paz e Segurança da Humanidade. In: TRINDADE, Antônio Augusto Cançado. Direitos Humanos e Meio Ambiente. Fortaleza: Expressão Gráfica e Editora, 2017. p. 51-76.

GRUSKIN, Sofia; TARANTOLA, Daniel. Health and Human Rights. In: GRUSKIN, Sofia et al. (ed.). Perspectives on health and human rights. Nova York: Routledge, 2005. p. 3-57

LEAL, César Barros. Breves notas sobre os refugiados ambientais e seu desafio na contemporaneidade. In: TRINDADE, Antônio Augusto Cançado. Direitos Humanos e Meio Ambiente. Fortaleza: Expressão Gráfica e Editora, 2017. p. 77-92.

LOUREIRO, Gustavo do Amaral; SALLES, Denise Mercedes N. N. Lopes. Da Emergência à Internalização: o direito humano à água no Brasil e na Argentina. In: SALLES, Denise Mercedes N. N. Lopes; GONÇALVES, Fernanda Cristina Nanci Izidro (org.). Relações Internacionais em Perspectiva (volume 2). Rio de Janeiro: Editora Multifoco, 2017. p. 18-64.

MARKS, Stephen P. The emergence and scope of the human right to health. In: ZUNIGA, José M.; MARKS, Stephen P.; GOSTIN, Lawrence O. (ed.). Advancing the Human Right to Health. Oxford: Oxford University Press, 2013. p. 3-24. https://doi.org/10.1093/acprof:0so/9780199661619.003.0001 MINISTÉRIO DAS CIDADES. Plano Nacional de Saneamento Básico. Brasília, maio de 2013.

ORELLANA, Marcos. The Case for a Right to a Healthy Environment. Human Rights Watch, $1^{\circ}$ de março de 2018. Disponível em: https://www.hrw.org/news/2018/03/01/case-right-healthy-environment. Acesso em: 18 dez. 2018.

ORGANIZAÇÃO DAS NAÇÕES UNIDAS. Report of the United Nations Conference on the Human Environment. Estocolmo, 5-16 de junho de 1972.

ORGANIZAÇÃO MUNDIAL DA SAÚDE. Declaration of Alma-Ata. Conferência Internacional sobre Cuidados Primários de Saúde, Alma-Ata, União das Repúblicas Socialistas Soviética, 6-12 de setembro de 1978. Disponível em: https://www.who.int/publications/almaata_declaration_en.pdf. Acesso em: 15 jan. 2019.

RUGGIE, John Gerard. Multilateralism: the Anatomy of an Institution. International Organization, [S. l.], v. 46, n. 3, p. 561-598, 1992. https://doi.org/10.1017/S0020818300027831

TRINDADE, Antonio Augusto Cançado. Os Direitos Humanos e o Meio Ambiente. In: SYMONIDES, Janusz (org.). Direitos Humanos: novas dimensões e desafios. Brasília: Edições UNESCO Brasil, 2003, p. 161-203.

VALVASSORI, Morgana Levati; ALEXANDRE, Nadja Zim. Aplicação do Indicador de Salubridade Ambiental (ISA) para áreas urbanas. Revista Brasileira de Ciências Ambientais, Rio de Janeiro, n. 25, p. 1-19, 2012.

VARGAS, Éverton Vieira. Água e relações internacionais. Revista Brasileira de Política Internacional, Brasília, v. 43, n. 1, p. 178-182, 2000. https://doi.org/10.1590/S0034-73292000000100010 
VASAK, Karel. A 30-year struggle: The sustained efforts to give force of law to the Universal Declaration of Human Rights. The UNESCO Courier, Ano XXX, v. 11, p. 29-32, 1977.

ZIGLIO, Luciana Aparecida lotti; COMEGNA, Maria Angela. Movimentos Socioambientais e Gestão dos Recursos Naturais no Cenário Amazônico: Ações da Confederação dos Povos Indígenas da Bolívia. Soc. \& Nat., Uberlândia, v. 25, n. 3, 2013, p. 513-523. https://doi.org/10.1590/S1982-45132013000300006 SATO, Eiiti. A agenda internacional depois da Guerra Fria: novos temas e novas percepções. Rev. Bras. Polít. Int., Brasília, v. 43, n. 1, 2000, p. 138-169. https://doi.org/10.1590/S0034-73292000000100007

Recebido: $17 / 04 / 2019$

Aceito: $16 / 07 / 2019$

\section{Biografia do autor}

\section{Gustavo do Amaral Loureiro}

Mestrando pelo Programa de Pós-Graduação em Ciência Política da Universidade Federal do Estado do Rio de Janeiro (UNIRIO). Bacharel em Relações Internacionais pelo Centro Universitário La Salle do Rio de Janeiro (Unilasalle-RJ). Pesquisador do Novas Fronteiras: Núcleo de Pesquisa em Migrações e Direitos Humanos e do projeto de pesquisa “Novas Práticas de Fronteira, Migrações e Direitos Humanos», ambos vinculados ao Centro Universitário La Salle do Rio de Janeiro (Unilasalle-RJ) e à Universidade Católica de Petrópolis (UCP). Bolsista CAPES. ORCID: http://orcid.org/0000-00027429-7172; E-mail: gus.amaral7@gmail.com

Instituição: universidade Federal do Estado do Rio de Janeiro, UNIRIO, Brasil

Localização: Av. Pasteur, 296 - Urca, Rio de Janeiro - RJ, 22290-250 